Open Access

\title{
The choice of pension and retirement systems when post-1960s baby boomers start to retire in China
}

Hualei Yang

Correspondence: hlep@cau.edu.cn School of Economics and

Management, China Agricultural University, Qing Hua East Road No. 17, Beijing 100083, China

\section{SpringerOpen}

\begin{abstract}
Background: Around 2015, with the alternation of population generation, post1960s baby boomers start to retire and post-1990s and 2000s baby busters successively enter into labor market in China, which has led to the decrease of working-age population, the increase of pension burden.

Methods: We use dynamic programming method by improving the traditional OLG model.

Results: This paper finds that a combination of immediately delayed retirement and accumulated pension system should be implemented if based on the goal of maximizing output, while a combination of undelayed retirement and accumulated pension system should be implemented if based on the goal of maximizing utility. Certainly, with using efficiency of elements unchanged, with the decrease of working-age population caused by the alternation of population generation, the increase of pension burden and the disappearance of capital dividend, a sharp decline of future economic growth cannot be changed no matter what kind of pension and retirement systems are implemented.

Conclusions: In view of the substitutability of family utility and social output and synthesizing reform resistance, a combination of gradually delayed retirement and accumulative pension system should be implemented. At the same time, on the premise of stabilizing short-term economic situation, we should look for a new engine for economic development by system reform in the long run.
\end{abstract}

Keywords: Retirement system, Pension policy, Post-1960s baby boomers, Social output and family utility

\section{Background}

Around 2015, with the alternation of population generation, post-1960s baby boomers start to retire and post-1990s and 2000s baby busters successively enter into labor market in China, which has led to the decrease of working-age population, the increase of pension burden, and the disappearance of demographic dividend in China (see Fig. 1). Labor engine for Chinese economy will flame out. If China's economy does not shift from depending on the quantity of labor force to depending on technology, capital, and population quality, while carrying out industrial updating, it is highly possible in the long run that China's economic will enter into the normal situation of low speed, fall into the middle-income trap (Cai 2011), and hit the demographic cliff according to the current development model. Technological progress, improvement of population

(c) 2016 The Author(s). Open Access This article is distributed under the terms of the Creative Commons Attribution 4.0 International License (http://creativecommons.org/licenses/by/4.0/), which permits unrestricted use, distribution, and reproduction in any medium, provided you give appropriate credit to the original author(s) and the source, provide a link to the Creative Commons license, and indicate if changes were made. 


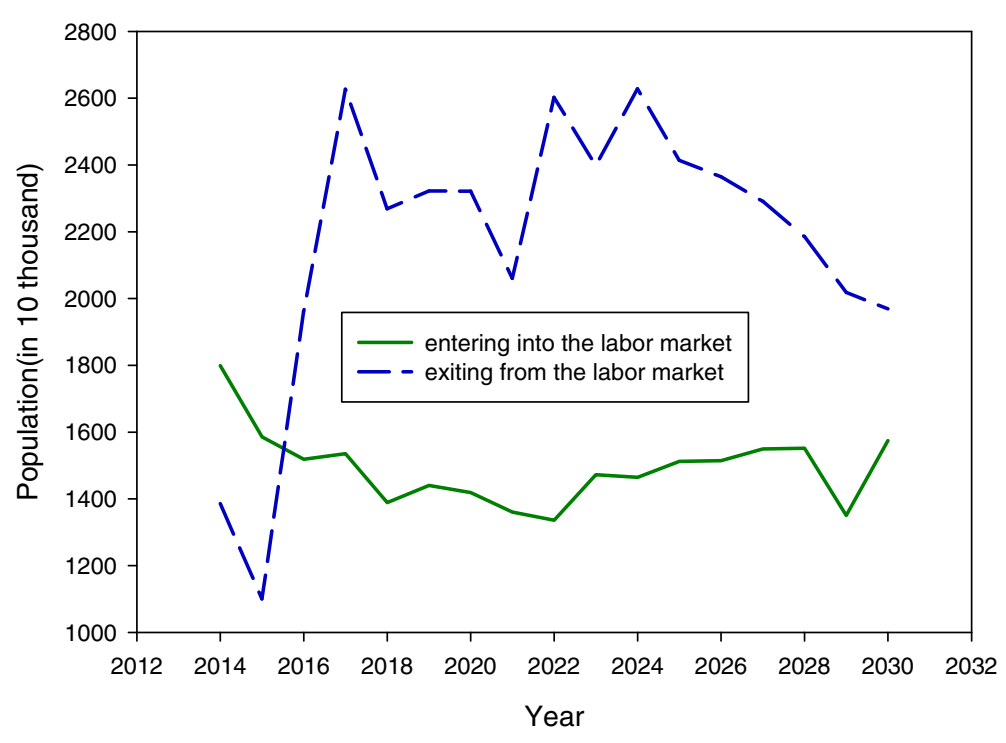

Fig. 1 Population of entering into and exiting from the labor market

quality, and upgrading of industrial structure cannot be realized in the short time. With the conversion of that demographic dividend turn into demographic debt, capital dividend will also gradually disappear. In order to equip the economy with a new engine and evade economic upheaval caused by sharp retirement of post-1960s baby boomers and win time for economic restructure, technological progress, the improvement of population quality, and upgrading of industrial structure in the long period, former engine must be remolded in the short period to stabilize the economy and make it advance slowly and then change her track. As regards remolding previous engine, for example, the calls for changing pension system and delaying retirement system in the short period to mitigate the impact of decrease of laboring population and excessive pension burden on economic system during the retirement period of post-1960s baby boomers are getting louder and louder in political circles and academy circles.

Along with the implementation of the new farmers' security in 2009, new endowment insurance for urban residents in 2010, and pension reform of public institution in 2015, China has formed a unified mode of the combination of social pooling and individual account, namely, the current system of supporting for the elderly is a mixture of family support and social pension; social pension system is a hybrid scenario of pay as you go system and funded system. China's current retirement system has been formed in 1978, the document stipulates that male workers and cadres retire at the age of 60 years old, female cadres retire at the age of 55 year old, female workers retire at the age of 50 years old, and the average retirement age is about 55 years old. Of course, there are a lot of contents on the reform of the pension and retirement system. Here, the author pays more attention to the reform of intergenerational distribution effect of pension system, and retirement mode choose according to retirement age. Based on the above key points of research, two important reforms on China's pension and retirement system are as follows, whether we should delay the retirement, or not and whether we should increase the accumulation effect of pension and the proportion of personal account in order to establish fully funded pension system, or not. 
For the above two scientific problems, different scholars have different opinions, for example, Yuan (2014) thought that delayed retirement could mitigate the gap size of pension and lessen finance stress for the government, the study on OECD countries showed that continued employment of the aged would not result in taking more positions which belong to the young (Kalwij et al. 2010), in fact, there is the complementarity between the employment of the aged and the employment of the young. Yang and Xie (2014) thought that, after entering into new normal, continued employment of the retiree would increase employment pressure on the young; Michello and Ford (2006) thought that delayed retirement would result in taking more positions which belong to the young, especially in those sections which already have surplus workers, et al. Therefore, whether delayed retirement should be implemented, or not, which is a question to answered explicitly. Different pension systems certainly have different features. Gayane (2015) thought funded pension system is more vulnerable to inflation risk, while in contrast, pay-as-you-go system does not have this problem. The future studies showed that in reality, if based on the perspective of maximizing investment and output, funded pension system is superior to pay-as-you-go system (Chybalski 2011); family support system exists widely in China's vast rural area; during the period of demographic dividend, we should universally implement pay-as-you-go system (Ke and Yuan 2004); what kind of pension mode should be chosen is a question which need to be answered urgently when post-1960s baby boomers start to retire in China.

With post-1960s baby boomers starting to reach retirement age and post-1990s and 2000s baby busters successively entering into the labor market, at the same time, the upgrading of industrial structure and the improvement of population quality cannot be realized in the short time. In terms of research questions, few literature, taking China's special national conditions into account (for example, China's fertility behavior is strictly controlled by population policy, child-rearing is not only consumer behavior but also is investment behavior, pension system is a hybrid scenario of PAYG system, fund pension system, savings and child support, after 2015, post-60s baby boomers will start to reach retirement age in succession, China implements universal two-child policy) analyzes various pension and retirement systems by considering fertility behavior, retirement system, and pension mode in one-model framework and selects pension and retirement systems which are suitable for future conditions in China based on some policy goals. In terms of research method, existing literatures mostly adopt overlapping generation model (OLG), but, in the next 15 years and short-term, the OLG model of examining intergenerational conversion, which cannot reflect the changes of annual output and family utility according with real situation, also cannot simulate the annual influence of post-1960s baby boomers' retirement on every aspect of socioeconomic system in the short time. Based on the defects of existing literatures, from the angle of maximizing social output and family utility, this article tries to give some alternative pension and retirement scenarios, and then tries to appraise those pension and retirement systems which may be put into effect by the government in the future by using the dynamic programming model, finally, chooses pension and retirement systems which are suitable for Chinese current and future national conditions.

\section{Methods}

Population can be divided into three types for any period: adolescent, adult, and the aged; the population at the age of 0-15 years old is defined as adolescent, while the age interval of adult and elderly population depends on the retirement system. Adolescents 
do not participate in social work, and the consumption of maintaining life only comes from parents' support; in the next period, some adolescents become adult. Adult supply labor for labor income each period, and in order to achieve maximum utility, adults make decision on how to allocate current labor income into consumption, savings, pension, supporting for the elderly, and child-rearing. Some adults become old people in the next period; here, we assume that total social utility is approximately equal to the utility of adult. Elderly population does not participate in work and does not make social decisions, such as fertility decision. Their income comes from pension, adult support, and savings; some elderly people will die in the next period. The utility function of adult includes two parts: current consumption utility stream and utility stream in the next period.

\section{Theoretical framework}

Following Barro and Becker (1989) and Liao (2013), utility function is set as follows, intertemporal substitution elasticity of consumption is $\sigma$, discount factor is $\beta$, the proportion of social pooling accounts pension to wage and the proportion of personal accounts pension to wage is $\tau_{1}$ and $\tau_{2}$ respectively, and the total proportion of pension to wage is $\tau=\tau_{1}+\tau_{2}$. For each subsequent period, we uniformity assume that the initial period is $i$, the proportion of family support for each elderly population to wage is $\phi$, and the proportion of family expenditure for each adolescent to wage is $\mu$. Consumption, savings for $i$-th period, and consumption for $i+1$-th period is $C_{i}^{1}, S_{i}$, and $C_{i}^{2}$, respectively. In the $i$-th period, the number of total population, adolescent, labor population (or adult), and elderly population is $P_{i}, H_{i}, L_{i}$, and $O_{i}$ respectively. The wage of $i$-th period, the wage of $i+1$-th period, and interest rates of $i+1$-th period is $w_{i}, w_{i+1}$, and $\mathrm{r}_{i+1}$, respectively. Relaxing fertility regulation does not affect human capital level of labor population before 2030. We assume that fertility level is exogenous, fully controlled by a fertility policy, and the fertility level of policy is equal to actual fertility level; according to this assumption, the total fertility rate (referred to as TFR) of universal two-child policy is about 2 .

We regard technological progress as system or reform bonus, pension system influences the setup of model and parameter, and delayed retirement does not influence the number of labor, but affect the number of retiree or pensioners. The number of population who are going to retire is $\mathrm{RE}_{i}$ for $i$-th period. The number of labor $L_{i}$ for $i$-th period is calculated according to the population (adult) of each age group and corresponding labor participation rate of each age group. Population at the age of $i$ years old is $P_{i}(j)$ for $i$-th period, labor force participation rate for the population aged $j$ years old is $\operatorname{ER}_{i}(j)$ for $i$-th period, in order to simplify the processing; each period, we suppose that labor force participation rate in each age group is fixed on the level of 2010 without affecting analytical results, so total number of labor for $i$-th period is as follows.

$$
L_{i}=\sum_{j=16}^{54} P_{i}(j) \mathrm{ER}_{2010}(j), i=2014,2015, \ldots, 2030
$$

The current tongzhang pension system (referred to as TZPS) is a combination of social planning pension (pay as you go system), individual accounts pension (accumulated pension system or funded pension system), and family support. According to its feature, labor income is $L_{i} w_{i}$ in the $i$-th period. It is spent on consumption $C_{i}^{1}$, savings $S_{i}$, child-rearing expense $H_{i} \mu w_{i}$, elderly-rearing expenditure $\phi w_{i} O_{i}$, social planning pension $\tau_{1} L_{i} w_{i}$, and individual account pension expenditure $\tau_{2} L_{i} w_{i}$.Consumption $C_{i}^{1}$ happens utility stream 
$\left(C_{i}^{1}\right)^{\sigma}$ in the $i$-th period. In the $i+1$-th period, savings $S_{i}$ obtains $S_{i}\left(1+r_{i+1}\right)$ unit income, $\tau_{2} L_{i} w_{i}\left(1+r_{i+1}\right)$ term is the return of $\tau_{2} L_{i} w_{i}$ term, $\tau_{1} L_{i} w_{i}+\frac{\tau_{1} L_{i+1} w_{i+1} \mathrm{RE}_{i}}{O_{i+1}}-\tau_{1} L_{i} w_{i} \mathrm{RE}_{i} / L_{i}$ term is the return of $\tau_{1} L_{i} w_{i}$. Taking investment culture on pension of bringing up child into account, so child-rearing expenditure $H_{i} \mu w_{i}$ and elderly-rearing expenditure $\phi w_{i} O_{i}$ obtain $\left(H_{i} \mu w_{i}+\phi w_{i} O_{i}\right)$ unit income in the $i$-th period. The term of consumption $C_{i}^{1}$ happens utility stream in the $i$-th period, the term of $S_{i}, \tau_{2} L_{i} w_{i}, \tau_{1} L_{i} w_{i}, H_{i} \mu w_{i}$, and $\phi w_{i} O_{i}$ happens utility stream in the $i+1$-th period. Under the TZPS, annual decision problem which labor population faces is how to choose consumption and savings in order to achieve maximized utility goal of annual labor income. Finally, objective function and constraints for $i$-th period are as follows.

$$
\text { s.t. }\left\{\begin{array}{c}
\operatorname{Max} U_{i}=\left(C_{i}^{1}\right)^{\sigma}+\beta\left(C_{i}^{2}\right)^{\sigma} \\
(1-\tau) L_{i} w_{i}=C_{i}^{1}+S_{i}+H_{i} \mu w_{i}+O_{i} \phi w_{i} \\
C_{i}^{2}=\left(S_{i}+\tau_{2} L_{i} w_{i}\right)\left(1+r_{i+1}\right)+\left(H_{i} \mu w_{i}+\phi w_{i} O_{i}\right)\left(1-\frac{\mathrm{RE}_{i}}{L_{i}}\right)+\mathrm{RE}_{i} \phi w_{i+1} \\
+\tau_{1} L_{i} w_{i}\left(1-\frac{\mathrm{RE}_{i}}{L_{i}}\right)+\tau_{1} L_{i+1} w_{i+1} \frac{\mathrm{RE}_{i}}{O_{i+1}} \\
\mathrm{RE}_{i}=P_{i}(j) \\
i=2014,2015, \ldots, 2030 \\
j=54,55, \ldots, 64 \\
0 \leq \sigma, \beta, \phi, \mu, \tau_{2}, \tau_{1}, \tau \leq 1
\end{array}\right.
$$

Following Barro and Lee (2010), firstly, we calculate average schooling years of labor population $s_{i}$ in the $i$-th period, then we calculate human capital level $h_{i}$ for $i$-th period according to PWT version 8.0. For each age group, we assume that $s_{i}(j)$ is the average years of schooling of each labor population aged $j$ years old for $i$-th period. $L_{i}(j)$ is the number of working people aged $j$ years old for $i$-th period. Finally, the average year of schooling per labor $s_{i}$ for $i$-th period is as follows.

$$
s_{i}=\sum_{j=16}^{54} L_{i}(j) s_{i}(j) / \sum_{j=16}^{54} L_{i}(j)
$$

Considering that average years of schooling $s_{i}$ for $i$-th period cannot directly enter into production function, we introduce the rate of return on average years of schooling. Finally, we regard human capital level $h_{i}$ as a function of average years of schoolings $s_{i}$, according to the function provided by Penn World Table 8.0, we can find

$$
h_{i}=e^{\phi\left(s_{i}\right)}, s_{i}=\sum_{j=16}^{54} L_{i}(j) s_{i}(j) / \sum_{j=16}^{54} L_{i}(j)
$$

Because education level shows discontinuous characteristic, so human capital function is a piecewise function. At the same time, many studies show that the return rate on early education is higher than that of later education, finally, referring to the research work of Psacharopoulos (1994), Lu and Cai (2014), $\phi\left(s_{i}\right)$ for $i$-th period is set as follows.

$$
\phi\left(s_{i}\right)=\left\{\begin{array}{c}
0.134 *\left(4-s_{i}\right), s_{i} \leqq 4 \\
0.134 * 4+0.101 *\left(s_{i}-4\right), 4<s_{i} \leqq 8 \\
0.134 * 4+0.101 * 4+0.068 *\left(s_{i}-8\right), 8<s_{i}
\end{array}\right.
$$

In the above model, we use C-D production function of constant return to scale and assume that contribution quotient of capital $\alpha$ is invariant. In order to simplify analytical process, we use average years of schooling $s_{i}$ to characterize human capital level of 
labor population. According to initial output in 2014, we assume that total factor productivity is a variable which is calibrated. Finally, production function for $i$-th period and production function for $i+1$-th period is set as follows.

$$
\left\{\begin{array}{c}
Y_{i}=A\left(K_{i}\right)^{\alpha}\left(h_{i} L_{i}\right)^{1-\alpha} \\
Y_{i+1}=A\left(K_{i+1}\right)^{\alpha}\left(h_{i+1} L_{i+1}\right)^{1-\alpha}
\end{array}\right.
$$

According to profit maximization conditions that capital marginal revenue is equal to interest rate and labor marginal revenue is equal to wage for each period. Capital marginal revenue is the first derivative of production function with respect to capital, labor marginal revenue is the first derivative of production function with respect to labor. TZPS is a combination of social planning pension, individual accounts pension and family support, the pension for personal accounts is cumulative, so current savings and individual account pension will increase capital stock of next period together. We assume that capital depreciation rate is $\delta$, savings is equal to investment, and corruption does not exist in the pension. The stock of capital $K_{i+1}$ for $i+1$-th period is equal to the sum of current stock of capital $K_{i}$, savings $S_{i}$ and pension $\tau_{2} L_{i} w_{i}$ in the $i$-th period, and then the above sum deducts depreciation $\delta K_{i}$.Finally, according to the above assumptions, the motion equation of capital for each period is set as follows

$$
K_{i+1}=(1-\delta) K_{i}+S_{i}+\tau_{2} L_{i} w_{i}, \quad i=2014,2015, \ldots, 2030
$$

How to calculate the motion equation of total population or labor population? Here, we follow Lu and Cai (2014)'s work and assume that fertility level is fully controlled by the fertility policy; under this condition, if we know policy fertility level for each period, and will also know initial population distribution and corresponding mortality at each age stage, we will also know future population distribution at each age stage. According to "2014 Chinese population and Employment Statistics Yearbook," TFR is about 1.3 in 2013, that is TFR of maintaining the fertility policy unchanged, the policy TFR of universal two-child policy is about 2.0.We put population distribution in 2014 for different gender at each age stage as an initial population distribution and put mortality between 2003 and 2013 for different gender at each age stage as population update criteria. Firstly, we calculate population distribution for different gender at each age stage, we get the number of people at each age stage by the sum of the number of population for different gender for each age stage, and then we get the total population by adding the number of the population at each age group. Secondly, the number of newborn babies every year depends on the number of women of childbearing age (aged 15-49) and corresponding fertility level at each age stage.

Under the condition of maintaining the fertility policy unchanged, the fertility rate at the age of childbearing for each age stage is given by 2013's Statistical Yearbook, where the TFR is about 1.3; compared to the fertility policy unchanged, universal two-child policy will improve the TFR at each age period by $50 \%$. Based on the above analysis, we can infer the sub-fertility level for different ages at the childbearing age under the universal two-child policy; at the same time, we assume that subsequent annual fertility level is unchanged after implementing universal two-child policy. Based on the above hypothesis, taking universal two-child policy into account, sex ratio of newborn babies will be eased, so we assume that future sex ratio for newborn babies is 110:100. Finally, the number of newborn babies for $i$-th period and different gender and the 
number of population for $i+1$-th period and different gender are respectively calculated as follows.

$$
\left\{\begin{array}{c}
P_{i+1}^{\text {male }}(j+1)=\left(1-d_{i}^{\text {male }}(j)\right) P_{i}^{\text {male }}(j) \\
P_{i+1}^{\text {female }}(j+1)=\left(1-d_{i}^{\text {female }}(j)\right) P_{i}^{\text {female }}(j) \\
P_{i+1}^{\text {male }}(0)=\frac{110}{100+110} \sum_{j=15}^{49} \operatorname{TFR}_{i}^{\text {female }}(j) P_{i}^{\text {female }}(j) \\
P_{i+1}^{\text {female }}(0)=\frac{100}{100+110} \sum_{j=15}^{49} \operatorname{TFR}_{i}^{\text {female }}(j) P_{i}^{\text {female }}(j)
\end{array}\right.
$$

The male and female mortality for $j$ years old in the $i$-th period is the variable $d_{i}^{\text {male }}(j)$ and $d_{i}^{\text {female }}(j)$ respectively, the male and female number of aged $j$ years old for $i$-th period is the variable $P_{i}^{\text {male }}(j)$ and $P_{i}^{\text {female }}(j)$ respectively, and the sub-fertility rate of female for $j$ years old in the $i$-th period is the variable $\operatorname{TFR}_{i}^{\text {female }}(j)$. It is important to note that this article assumes that people's lives are limited, the maximum life span is 100 years old, and individuals for more than 100 years old will automatically exit the model. According to the above update law, we calculate the total population by adding the number of population for a different age group and gender in the next 15 years. Considering China law, population are not allowed to take part in labor until 16 years old and the population of less than 16 years old is called adolescent. According to the characteristics of China's current retirement age, at the same time, we no longer distinguish between urban and rural or for different sectors. We assume that the average retirement age is approximately 55 years old, and the retirement system does not affect the number of working people, but affect the number of the people receiving the pension. So the population of 16-54 years old is called the working-age population, and the population who is over the age of 55 who receive the pension is called the elderly or pensioners.

It should be noted that the working-age population is not equal to the actual number of the labor population; this is because there are some variables, such as labor force participation and unemployment, but there are some scenes, for example, on workingage population participating in the labor. Taking Chinese law, retirement age, and research question into account, we ignore the scenario of non-labor population participating in the labor. The labor participation rate for $j$ years old and $i$-th period is $\operatorname{ER}_{i}(j)$; here we put labor participation rate of sixth census at each age stage as initial labor participation rate. At the same time, labor participation rate is assumed to be unchanged for subsequent period. If the number of population for $j$ years old and $i$-th period is $P_{i}(j)$. Finally, the motion equations for population are as follows.

$$
\left\{\begin{array}{c}
P_{i}=\sum_{j=0}^{100}\left(P_{i}^{\mathrm{female}}(j)+P_{i}^{\text {male }}(j)\right) \\
H_{i}=\sum_{j=0}^{15}\left(P_{i}^{\mathrm{female}}(j)+P_{i}^{\text {male }}(j)\right) \\
L_{i}=\sum_{j=16}^{54} P_{i}(j) \mathrm{ER}_{2010}(j), P_{i}(j)=P_{\mathrm{i}}^{\mathrm{female}}(j)+P_{i}^{\text {male }}(j) \\
O_{i}=\sum_{j=55}^{100}\left(P_{i}^{\mathrm{female}}(j)+P_{i}^{\text {male }}(j)\right)
\end{array}\right.
$$

According to the hypothesis that fertility level is exogenous, as a result, population structure is known every year. At the same time, we put motion equation of capital and human capital into the next stage of production function. Meanwhile, in order to make initial human capital level become one unit, we introduce a multiplier $1 / h_{2014}$, so computational level of human capital for $i$-th period is $h_{i} / h_{2014}$ in actual simulation. Finally, 
under the TZPS, annual decision problem which labor population faces is how to choose consumption and savings per year in order to achieve the goal of maximizing utility of labor income in the mechanism of raising children to provide against old age, objective function, and constraints are set as follows every year.

$$
\text { s.t. }\left\{\begin{array}{c}
\operatorname{Max} U_{i}=\left(C_{i}^{1}\right)^{\sigma}+\beta\left(C_{i}^{2}\right)^{\sigma} \\
(1-\tau) L_{i} w_{i}=C_{i}^{1}+S_{i}+H_{i} \mu w_{i}+O_{i} \phi w_{i} \\
C_{i}^{2}=\left(S_{i}+\tau_{2} L_{i} w_{i}\right)\left(1+r_{i+1}\right)+\left(H_{i} \mu w_{i}+\phi w_{i} O_{i}\right)\left(1-\frac{\mathrm{RE}_{i}}{L_{i}}\right)+\mathrm{RE}_{i} \phi w_{i+1} \\
+\tau_{1} L_{i} w_{i}\left(1-\frac{\mathrm{RE}_{i}}{L_{i}}\right)+\tau_{1} L_{i+1} w_{i+1} \frac{\mathrm{RE}_{i}}{O_{i+1}} \\
\mathrm{RE}_{i}=P_{i}(j) \\
w_{i}=A(1-\alpha)\left(h_{i} / h_{2014}\right)^{1-\alpha}\left(K_{i}\right)^{\alpha}\left(L_{i}\right)^{-\alpha} \\
w_{i+1}=A(1-\alpha)\left(h_{i+1} / h_{2014}\right)^{1-\alpha}\left((1-\delta) K_{i}+S_{i}+\tau_{2} L_{i} w_{i}\right)^{\alpha}\left(L_{i+1}\right)^{-\alpha} \\
r_{i+1}=A \alpha\left(h_{i+1} / h_{2014}\right)^{1-\alpha}\left((1-\delta) K_{i}+S_{i}+\tau_{2} L_{i} w_{i}\right)^{\alpha-1}\left(L_{i+1}\right)^{1-\alpha} \\
K_{i+1}=(1-\delta) K_{i}+S_{i}+\tau_{2} L_{i} w_{i} \\
h_{i}=e^{\phi\left(s_{i}\right)} \\
L_{i}=\sum_{j=16}^{54} P_{i}(j) \mathrm{ER}_{2010}(j) \\
j=54,55, \ldots, 64 \\
i=2014,2015, \ldots, 2030 \\
0 \leq \sigma, \beta, \phi, \mu, \tau_{2}, \tau_{1}, \tau \leq 1
\end{array}\right.
$$

To be sure, under the universal two-child policy, firstly, retirement system affects the number of people who receive a pension each year; for example, according to current average age of receiving pension, if retirement system remains unchanged, the number of people who will retire for $i$-th period is $P_{i}(54)$, so different retirement systems mean different value of $R E_{i}$. Of course, the above implies an important hypothesis that the number of new pensioners each year is equal to the number of people who will be retiring. Secondly, different parameter combinations imply different pension systems; for example, pension system is the accumulated pension system or personal account pension (fully funded pension system, referred to as APS) when $\tau_{2}$ is equal to $t$ and $\tau_{1}$ is equal to 0 , pension system is social planning pension or pay as you go system (referred to as PAYGS) when $\tau_{1}$ is equal to tand $\tau_{2}$ is equal to 0 , and pension system is TAPS when $\tau_{2}>0$ and $\tau_{1}>0$. Technological progress is seen as institutional dividend in this paper; of course, the reform of pension system and retirement system can release productivity level.

\section{Parameter settings}

We calculate human capital level of each age segment by using split generation method, and the results were based on the work of Huang (2011), which accounted for average years of schooling of post-1950s, 1960s, and 1970s. At the same time, according to follow-up survey on schooling years of post-1980s in 2014 by Shanghai Jiao tong University, we successively set that average years of schooling is 12.5 years for post1980s, 14.5 years for post-1990s, and 16 years for post-2000s in China. Of course, if we reduce this standard of schooling settings, conclusions based on simulation will be more robust. In addition to consumption and savings, other exogenous variables and parameters are either given or determined by initial conditions or obtained by initial calibration. Finally, according to existing literatures and China's census data, parameter settings are shown in Table 1. 
Table 1 Various parameters and value setting

\begin{tabular}{lll}
\hline Parameters & Value setting & Setting basis \\
\hline$K_{i}$ (million) & $1,329,516$ & Gu and Zhang (2012) \\
$L_{i}$ (person) & $656,863,206$ & Sixth census data \\
$a$ & 0.5 & Lu and Cai (2014) \\
$A$ & 0.021455305 & Calibrated \\
$\sigma$ & 0.95 & Yang (2006) \\
$\beta$ & 0.98 & Liao (2013) \\
$\delta$ & 0.05 & Lu and Cai (2014) \\
$\mu$ & 0.2 & Liao (2013) \\
$\phi$ & 0.1 & Yang et al. (2015) \\
\hline
\end{tabular}

\section{Results and discussions}

In view of difference on gender and department of China's retirement age, meanwhile, the research emphasis of this paper is the comparison of different pension and retirement systems and the hypothesis that retirement age is equal to the age of receiving pension, the average age of receiving pension under the undelayed retirement is uniformly assumed to be 55 years old without influencing analysis results. At the same time, we no longer distinguish the difference on gender and department. According to the above analysis, we choose three types of retirement system: first, undelayed retirement system (referred to as UDR), with average retirement age at 55 years old; second, immediately delayed retirement system (referred to as IDR), with initial retirement age at 55 years old, uniformly put off the retirement age of people who is still on duty until 65 years old, and then fix it; and third, gradually delayed retirement system (referred to as GDR), there is a queue to retire every other year, and retirement age after 2035 is fixed at 65 years old.

Retirement system does not affect the number of adolescent, but influences the number of adult and the aged. According to the above model setting, we choose three kinds of pension scenarios: first, according to the characteristics of current pension system and the share of capital contribution in China, accumulated pension system led by the government (referred to as APS), $\tau_{2}$ is equal to $\tau=0.14$, and $\tau_{1}=0$; second, pay-as-you-go system led by the government (referred to as PAYGS), $\tau_{1}$ is equal to $\tau=0.14$ and $\tau_{2}=0$; and third, the current tongzhang pension system (referred to as TZPS), according to the characteristics of current pension system and the share of capital contribution in China, we give a parameter combination of $\tau_{1}=0.1$ and $\tau_{2}=0.04$. Of course, our study is based on the context of universal two-child policy. At the same time, we assume that actual fertility level is equal to policy fertility level. Based on the above hypothesis, we will examine the influence of various retirement and pension scenarios on social output and family utility and then select suitable retirement and pension scenarios according to some policy goals. Of course, comparative results of different retirement or pension system scenarios are robust for other parameter scenarios. Due to space limitation, author will not list other simulation scenarios; the specific solution process is shown in Additional file 1. Because different retirement system and pension system only affect population structure and parameter value of $\tau_{1}$ and $\tau_{2}$, here, we only give a scenario code under the condition of UDR and TZPS; you can acquire the other simulation results for the other scenarios by giving other population structure and parameter value of $\tau_{1}$ and $\tau_{2}$. 
To be sure, the following analyses are obtained under some assumptions such as immigration policy remaining unchanged, the share of capital contribution remaining unchanged, without regard to the differences in sex and between rural population and urban population, investment equaling to savings; no idle pension and no corruption in the pension; the pension of accumulative system all taking part in investment, same returns of savings and pensions; regarding technological progress as reform dividend, exogenous fertility level, factor (labor and capital) reward paid according to marginal output and no industrial updating; the age of receiving pension equaling to retirement age, retirement system which only affects the number of pensioners; and so on.

\section{Population structure in the future}

With the change of population generation, post-1960s baby boomers gradually enter into labor market. From Fig. 2, we can see that, firstly, after 2015, China's elderly dependency ratio show a linear upward trend and increase by about 2 percentage points per year. Secondly, there is a slight increase in dependency ratio in the future which increase by about 0.6 percentage points per year. Thirdly, China's total social dependency ratio shows a sharp upward trend which is mainly dependent on the rising trend of elderly dependency ratio. In short, accompanied by China's post-1960s baby boomers enter into retirement age. China's aging does show accelerated trend. At the same time, prior to 2030, the universal two-child policy adopted by current government cannot reduce elderly dependency ratio and total social dependency ratio, so we need to reform pension system and retirement system to buffer the impact of retirement tide on social and economic system in the critical period of achieving two goals of 100 years and the access to developed countries.

\section{Policy selection based on the goal of social output}

As is seen from Figs. 3 and 4, with fertility policy remaining unchanged, no matter what kind of pension and retirement scenarios, gross output and per capita output all shows a rapidly increased trend. Under the same retirement system, gross output and per

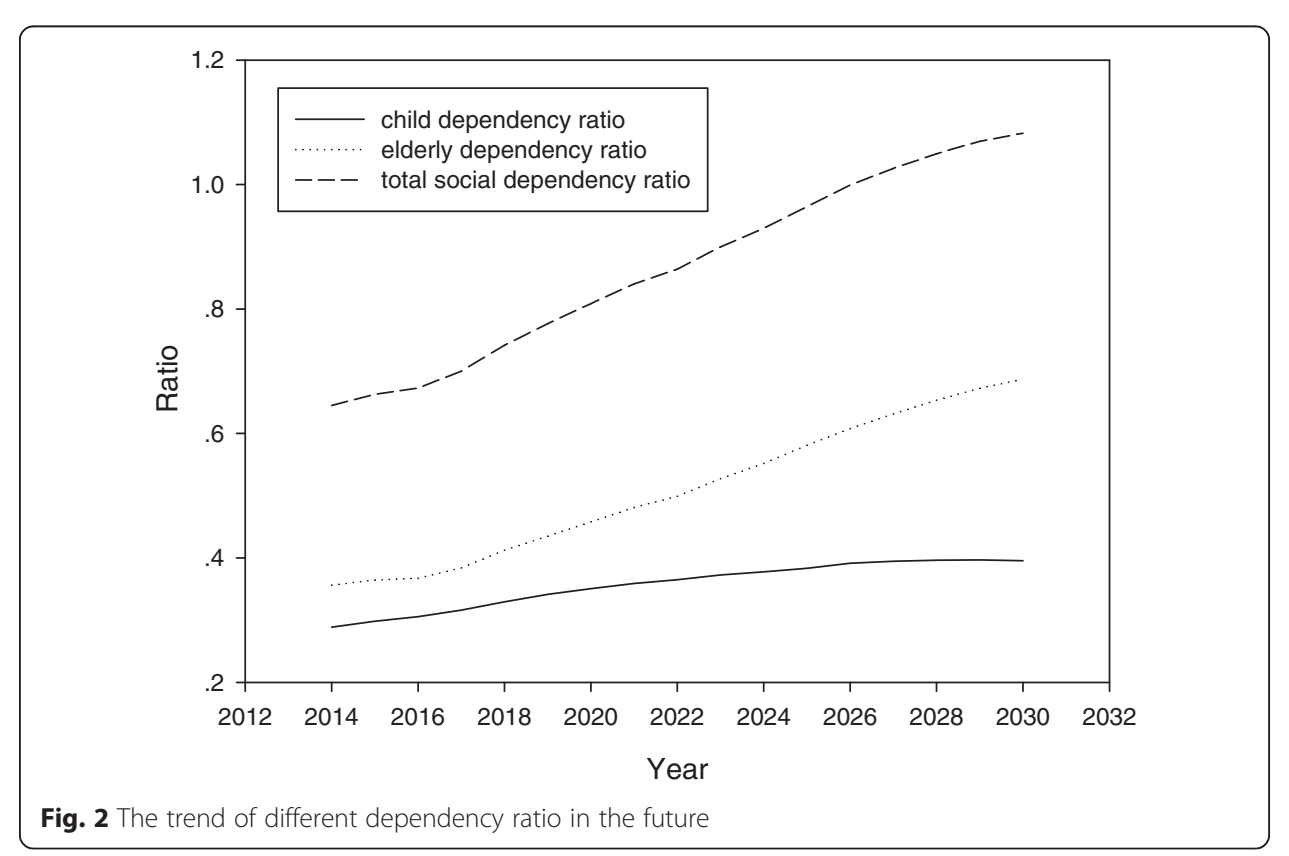




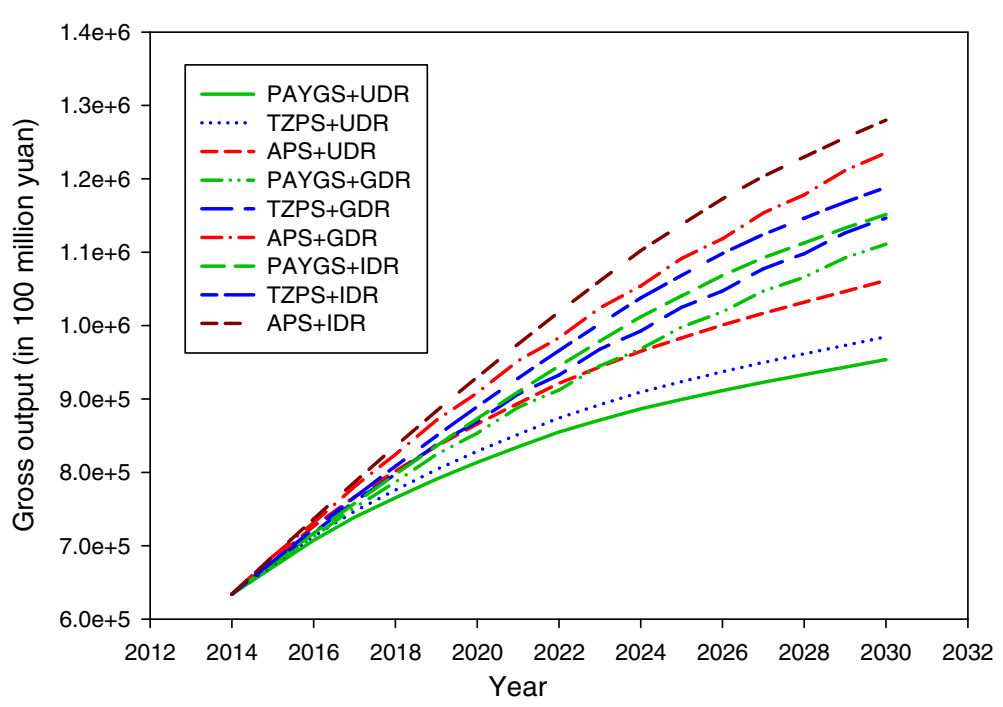

Fig. 3 Gross output for different pension and retirement scenarios

capital output of PAYGS is the lowest, gross output and per capita output of APS is the highest, and TZPS which is implementing by current government, is the middle. No matter what kind of pension system, gross output and per capital output of delayed retirement is higher than that of undelayed retirement, and IDR's gross output and per capita output is higher than that of GDR. Under the same pension system, if based on the perspective of maximizing gross output and per capita output, the government should give the preference to the IDR, and also due to the lowest gross output of PAYGS under the same retirement system, the higher effect of APS on output and per capita output, a combination scenario of APS and IDR should be chosen.

Why is the per capita output and gross output of PAYGS is the lowest? Firstly, relative to APS and TZPS, after 2015,with post-1990s and 2000s baby busters successively

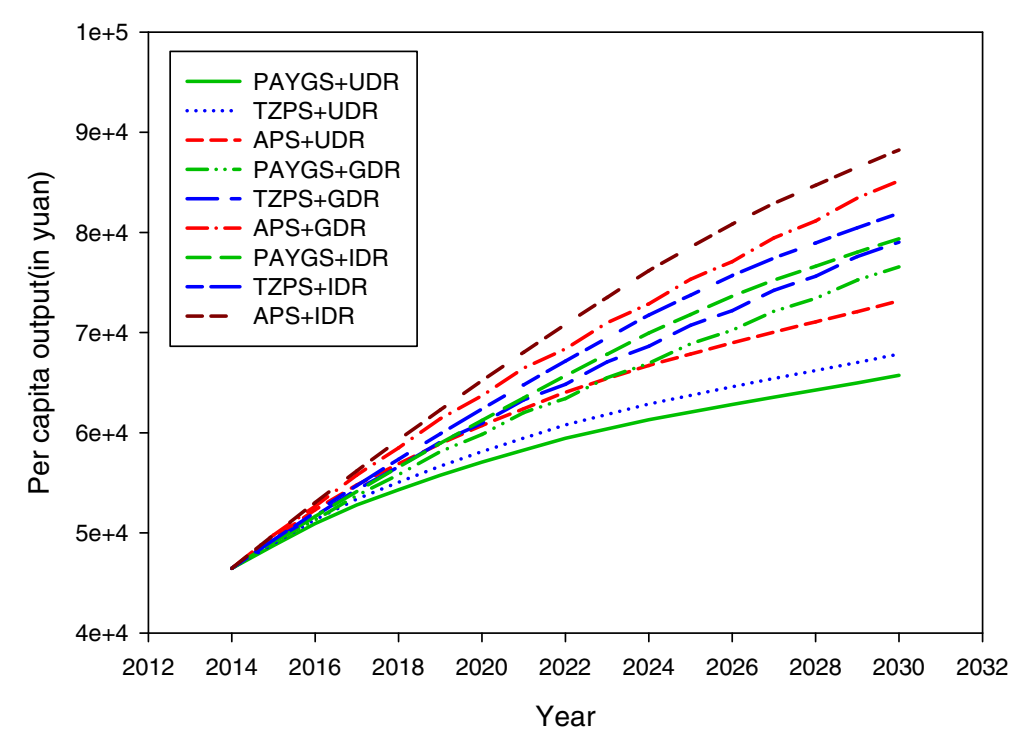

Fig. 4 Per capita output for different pension and retirement scenarios 
entering into labor market and post-1960s baby boomers just now starting to reach the age of receiving pension, the PAYGS of current young people supporting current old people will make pension outlay of Chinese economy already lack of labor force more bigger, reduce household savings and social investment, which will lead to the decrease of capital stock; secondly, relative to APS and TZPS, the pension of PAYGS does not take part in future production and increase capital stock. Therefore, its output and per capita output is more lower than that of TZPS and APS. Why gross output and per capita output of TZPS is lower than that of APS? TZPS is a pension system dominated by PAYGS, compared to APS. Its cumulative effect and capital increase effect is weaker than that of TZPS. In the case of same number of labor population, TZPS has lower capital stock, so gross output and per capita output of TZPS is lower than that of APS.

Why is output and per capita output of IDR higher than that of GDR? After 2015, in the case of largest post-1960s baby boomers gradually exiting labor market in China, the number of the aged will increase rapidly and the number of working-age population will decrease sharply in the future. According to the attributes of IDR, no working-age population will retire until 2025. Based on the features of GDR, only a wave people will retire each other year after 2015. Working population retires every year for UDR scenario. Under the condition of the same labor inflow, the labor outflow of UDR is stronger than that of GDR, and the outflow of GDR is stronger than that of IDR. So delayed retirement system increases the future number of labor population, reduces pension spending, increases capital stock, and thereby increases output and per capita output. Of course, the output effect of IDR is stronger than that of GDR.

\section{Policy selection based on the goal of family utility}

Utility value of objective function maximization of labor population is regarded as overall social welfare or total utility. The total utility divided number of labor population is regarded as per capita social welfare level or per capita utility level. As shown in Fig. 5, on per capita utility level, no matter under what kind of pension systems, UDR is all

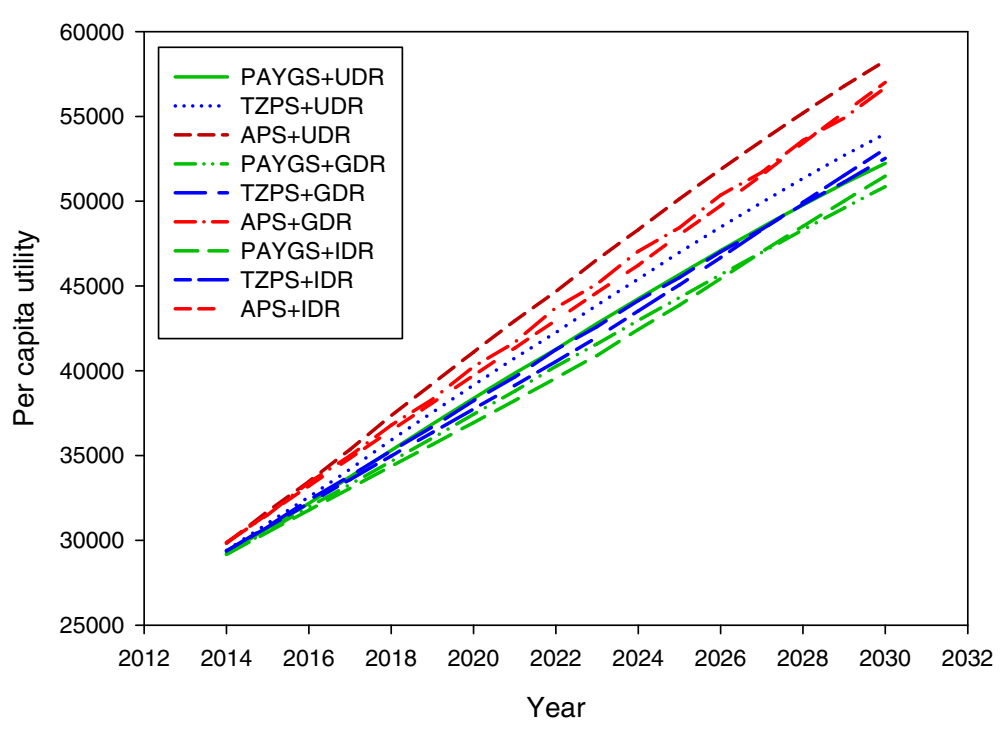

Fig. 5 Per capita utility for different pension and retirement scenarios 
the highest, followed by GDR and IDR; no matter under what kinds of retirement systems, PAYGS is all the lowest. APS is higher than TZPS. If a country wants to maximize per capita utility, no matter under what kinds of pension systems, it should give priority to UDR system, while discarding IDR. From the perspective of per capita utility maximizing, UDR and APS should be implemented; if taken into account the reform difficulty and based on the goal of maximizing per capita utility, then a combination of GDR and APS system should be selected.

Why per capita utility under delayed retirement is lower than that of undelayed retirement scenario? With average life expectancy unchanged, delayed retirement means the extension of working time, consumption postponement and compulsory savings, and the increase of capital stock, so, it increases output. But under the assumption of an economic man, due to the utility of future consumption per unit is lower than that of present consumption per unit, so per capita utility will decrease according to objective function. That is, every worker under the condition of delayed retirement will have to work longer than before, become more patient with economic prospect and reduce more present consumption to increase savings, and provide more heritages to their children. Delayed retirement also means that the labor population have to work longer, receive much less pension, and carry on less present consumption and private consumption because discount factor is less than 1 and people give larger weight to present consumption and private consumption. Therefore, delayed retirement will decrease per capita utility for every adult.

\section{Policy selection based on the goal of economic growth}

As shown in Fig. 6, with fertility policy and factor efficiency remaining unchanged, the sharp decline trend of economic growth cannot be changed by the reform of pension and retirement system; but the comparison results of pension and retirement systems on economic growth is roughly analogous to that of pension and retirement system on gross output and per capita output. The difference is that economic growth will enter

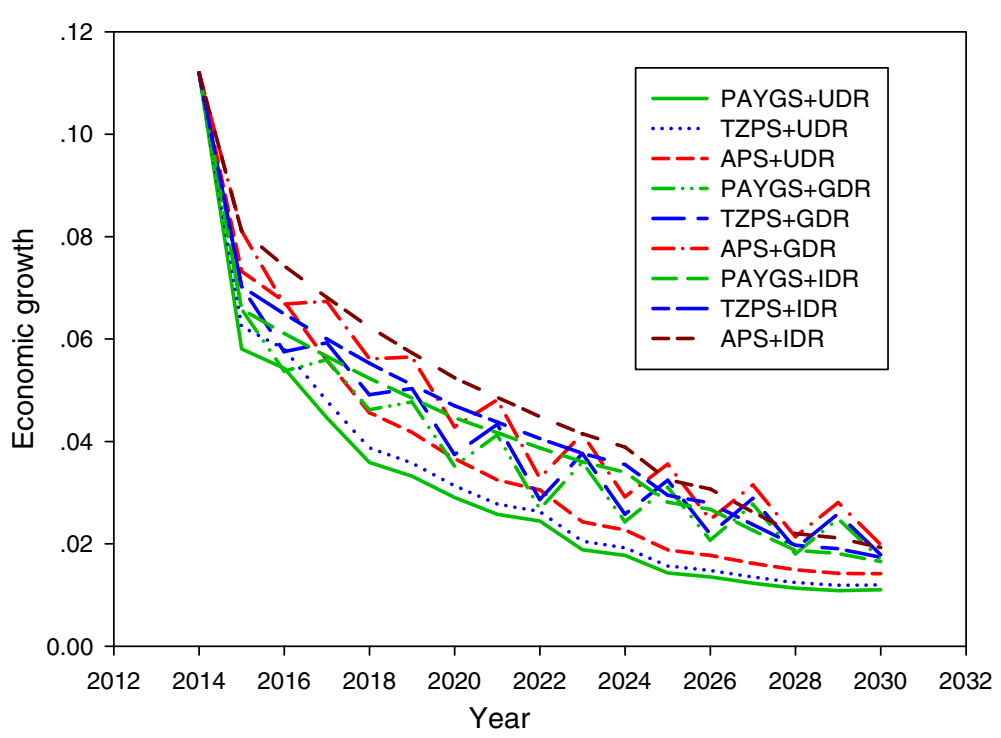

Fig. 6 Economic growth for different pension and retirement scenarios 
into new situation of low speed in the future, while gross output and per capita output still show an increasing trend. In fact, China's economy has hit demographic cliff; the reform influence of pension or retirement system on the trend characteristic of economic growth in the next 15 years will be insignificant. When the policies of blocking labor outflow do not work, there is something wrong with the labor inflow.

Post-1990s and 20000s are the baby busters in China, with post-1990s and 2000s baby busters gradually entering into the labor market after 2015, even if there is no labor outflow, due to the birth decrease year by year after 1987; 20 years later, the number of entrant entering into the labor market present a decreasing trend. The economic growth will only depend on the growth of labor population when capital growth and technology level remain unchanged. So, accompanied by a decline in the growth of labor population, economic growth will also show a corresponding decline trend. Of course, the delay in retirement and the reform in pension system only reduce the extent of decline, but do not change the decline trend. More seriously, after 2015, if we take successive retirement of post-1960s baby boomers into account, the extent of decline will be greater, ensuing demographic debt as well as gradual disappearance of capital dividend. Under the condition of unchanged production mode, China's economy will fall into demographic cliff.

\section{Conclusions}

Around 2015, due to the decrease of working-age population and dramatic increase of the aged caused by the alternation of population generation, in order to win time for the upgrading of industrial structure, the improvement of population quality and technological progress, and also to mitigate the impact of fast aging on economic system, it is necessary to look for suitable retirement and pension systems. Of course, there are a lot of contents on pension and retirement reform. In this paper, the author pays more attention to choose pension mode based on intergenerational distribution and choose retirement mode ignoring industry and regional and gender differences.

Simulation results show that no matter under what kind of retirement system, output and per capita utility of PAYGS is the lowest and output and per capita utility of APS is higher than that of TZPS. No matter under what kind of pension system, the output of IDR is the highest, followed by GDR and UDR; while on per capita utility level, no matter under what kind of pension system, UDR is the highest, followed by GDR and IDR. For a country, if based on the goal of maximizing output, a combination of IDR and APS should be implemented. If based on the goal of maximizing per capita utility, a combination of UDR and APS should be implemented. Taking reform resistance, output goal, and welfare goal into account, a compromise scheme which is a combination of GDR and APS should be implemented. Of course, the current TZPS is only a transitional pension system; APS is that we should choose in the aging society. It is gratifying that China is formulating a gradual retirement scheme and will try to carry out fully funded pension system.

Of course, there are a lot of reforms on the pension and retirement system in China. The above study is merely to provide the reader a reform direction on pension and retirement system. Pension and retirement system reform in China is a systematic and complex issue. Only if we take the combination of the pension reform can we achieve the desired policy goals. We not only deal with the relationship between the intergeneration but also have to deal with the relationship between the central and 
local governments; we not only delay retirement age based on life expectancy but also develop different retirement system for different industries and gender, which are the directions for future research.

\section{Additional file}

Additional file 1: Simulation code. (DOCX $31 \mathrm{~kb})$

\section{Acknowledgements}

My deepest gratitude goes first and foremost to peer reviewers, thank you for their constructive comments which help author make paper more perfect. Second, I would like to express my heartfelt gratitude to Prof. Huang Shaoan, Prof. Zhao Wenzhe, and Hu sen, from who the author has received valuable comments. Lastly, my thanks would go to my wife and my mother for their loving considerations and great confidence in me all through these years. All the errors remaining are the author's.

\section{Author's information}

Hualei is a PHD candidate in the School of Management, China Agricultural University. He conducted several researches in population economics and public economics.

\section{Competing interests}

The author declares that he have no competing interests.

Received: 2 February 2016 Accepted: 30 June 2016

Published online: 22 July 2016

\section{References}

Barro T, Becker GS (1989) Fertility choice in a model of economic growth. Econometrica 57(2):481-501 Barro J, Lee JW (2010) A new data set of educational attainment in the world 1950-2010. NBER Working Paper No. 15902. Cai F (2011) How long China's demographic dividend can last. Econ Perspect 101((6):3-7

Chybalski $F$ (2011) The resilience of pension systems in the CEE countries to financial and economic crisis: the need for higher diversification. 13th International Conference of Finance and Banking.

Gayane B (2015) A comparison of PAYG and funded pension systems. Arme J Econ 12(1):57-70

Gu MM, Zhang Y (2012) Estimation and decomposition of China's capital stock. Econ Theory Bus Manage 45(12):45-49 Huang CX (2011) Change of education attainment between 1964-2005 in China [J]. Popup J 188(4):3-14

Kalwij A, Kapteyn A, DeVos K (2010) Retirement of older workers and employment of the young. Economist 158(4):341-359

Ke Z, Yuan ZG (2004) Dynamic efficiency and the model for funding raising schemes of the pension system. J World Econ 103(5):3-12

Liao PJ (2013) The one-child policy: a macroeconomic analysis. J Dev Econ 101(1):49-62

Lu Y, Cai F (2014) Impact of demographic change on potential growth rate: comparison between China and Japan. J World Econ 104(1):3-29

Michello FA, Ford WF (2006) The unemployment effects of proposed changes in social security's normal retirement age. J Bus Econ 41(2):38-46

Psacharopoulos G (1994) Returns to investment in education: a global update. World Dev 22(9):1325-1343

Yang ZH (2006) Government consumption and household consumption: alternative and inter-term replacement. J World Econ 96(8):37-46

Yang YN, Xie Y (2014) The effect of the delayed retirement age on young unemployment. Chin Popup Sci 33(4):47-57

Yang HL, Zhou XB, Hu Z (2015) The effects of retirement plans and pension system on output and welfare. Insur Stud 53(5):106-120

Yuan $L$ (2014) Can delay retirement pension funds to solve the problem. Popup Econ 33(4):23-54

\section{Submit your manuscript to a SpringerOpen ${ }^{\circ}$} journal and benefit from:

- Convenient online submission

- Rigorous peer review

- Immediate publication on acceptance

- Open access: articles freely available online

- High visibility within the field

- Retaining the copyright to your article

Submit your next manuscript at $>$ springeropen.com 